\title{
Development of Human Balance Capability Testing Prototype
}

\author{
Aleksandrs Gorbunovs, Zanis Timsans, Atis Kapenieks, Rudolfs Gulbis \\ Riga Technical University, Distance Education Study Centre ${ }^{1}$, Address: Kronvalda Blvd.1, Riga, LV-1010, \\ Latvia
}

\begin{abstract}
The detection of human balance functional disorders may provide some kind of awareness or even warning about potential problems for human health both in organs responsible for ensuring the balance function and in organs related to fulfilment of other important life functions. Modern world offers some sophisticated solutions which enable not only determination of the human balance functional capacity but also offer some kind of training environment to provide corresponding rehabilitation. Unfortunately, such systems are very expensive. And this make limitations of their accessibility and practical usability for a wide range of the target group / population. Software solutions, including mobile applications, on the other hand, are incomparably cheaper. However, they do not allow to make precise balance capability measurements, limiting to simplified balance retention simulators.

During implementation of the Latvian National State Research Program VPP INOSOCTEREHI from 2015 to 2017 three human balance capability testing prototypes were developed using a variety of electronic and mechatronic solutions. The last one was successfully approbated during two pilots in Latvian schools in 2016 and demonstrated at the International Invention and Innovation Exhibition MINOX-2016. This paper analyses benefits and disadvantages of approaches used in creating of these prototypes. Besides, authors make initial comparison of developed third prototype version against the BioSway system offered in the market. The paper gives also insight into particular system interface development and new effective graphic portrayal of the balance testing output data, as well as sets the goals for further possible commercialization of the developed balance testing prototype.
\end{abstract}

Keywords: balance disorder; circuit; microcontroller; sensor.

\section{INTRODUCTION}

Modern society benefits from innovations in technology. Life expectancy is growing due to advances in medical, care and rehabilitation services. However, about one billion people, according to the World Bank and World Health Organization report, suffer from different kinds of disabilities [1], [2]. Each year this number increases. One part of persons with disabilities are born with the hereditary illnesses and functional disorders, but another one - got disability during life: due to some illnesses or at work; for example, approximately 3 per cent of employees in Europe got injured at the workplace [3]. World countries are faced with more than 9 health year losses in an average caused due to population disabilities and chronical illnesses [4]. State and local authorities take measures to reintegrate these people into work and society activities, enhance social inclusion processes [3]. Moreover, the world population is aging. This phenomenon impacts their ability to walk, care themselves, actively participate in everyday activities. It means that also this social group requires society attention and care.

In many cases functional disorders and injuries restrict ability of persons with disabilities to be involved in society activities, and decrease their life quality. Walking and postural ability trainings become essential, especially for elderly people and persons after stroke [5].

Social rehabilitation ought to be considered as the key component to improve the quality of life of elderly people, persons with disabilities and special needs. Taking into account that many physical disabilities and illnesses are closely tied with central nervous system functionality, and postural stability in particular [6], the human balance capability assessment equipment could be considered as the one of the tools which may help in early diagnosis of possible functional disorders.

At the moment, the industry offers a variety of systems and tools which can test patient postural stability. Unfortunately, they are rather expensive to be used in all involved respective rehabilitation organisations. This make limitations of their accessibility and practical usability for a wide range of the target group / population.

Software solutions, including mobile applications, on the other hand, are incomparably cheaper. However, they do not allow to make precise balance capability measurements, limiting to simplified balance retention simulators.

Our aim is to propose solutions and ensure development of portable, efficient and low-cost human balance disorder assessment equipment which 
would be accessible for the wide range of social groups not only at the rich medical centres, but also at all public and private medical, social rehabilitation and care organisations, schools, sport teams, army bases, and even at home.

\section{MATERIALS AND METHODS}

In order to reach defined goals, we have investigated the newest technical solutions which were implemented or offered for implementation in practice. Existing commercial systems and mobile applications were also studied. These findings helped us to develop a few human balance disorder assessment prototype models.

It was found that one of the most important market leaders in balance assessment field is the Biodex company. In particular, its Biosway system allows assessing person's balance capability rather precise [7]. It includes balance assessment part, consisting of the balance board with the hard and foam surfaces and the monitor to follow up on exercise implementation process and results. Training via gaming modes are also included. The system provides reporting about fulfilled tests. System's disadvantage - its expensive cost.

The Nintendo Wii Balance Board, mainly known as a gaming console, due to embedded pressure sensors, may also serve as an equipment for balance disorders assessment, postural stability training and improvement [8], [9]. Video games in combination with postural stability exercises in a form of physical activities, so called - exergaming, can improve human balance capabilities. Especially it applies for elderly people [10]. Despite apparent advantages this system has also some limitations in hardware and software caused by its commercial base.

One of promising findings and developments in the field of balance disorder assessment in a form of the balance board device for home care and exergaming was presented by Italian researchers [11], [12], who demonstrated very encouraging results in rehabilitation of post-stroke patients. However, still there is a set of research directions to be covered in order to solve early balance disorder assessment problem, for instance, availability to assess possible postural sways by appropriate scientifically recognized tests [13], use of different foam pads, ensure patient safety and stability during exercises.

Available on the market mobile applications, such as iBEST and similar ones [14], offer various ways to train personal balance capability. They successfully utilize potentialities of built-in sensors to determine possible balance disorders, monitor test, exercise or game fulfilment and provide feedback. Though, the validity of obtained postural sway data by mobile applications needs to be improved in order to give for a patient credible recommendations regarding further rehabilitation and / or visiting a doctor.
Pursuant to abovementioned considerations it was decided to start development of the new balance capability testing prototype. It ought to be rather inexpensive, easy to use, and ensure efficient postural sway detection.

Necessary programming tools for the prototype creation were chosen from available open source software in order to decrease project expenses. Wooden materials were used to create three prototype constructions. Used materials, including electronics, are shown in the next section together with the description of developed models and achieved results.

Developed prototypes were approbated in testbeds at the university and the first trials in schools, as well at the international exhibition. Obtained feedback and lessons identified gave the directions for further improvements.

Human balance assessment was made by employing Modified Clinical Test of Sensory Organization and Balance (mCTSIB) test [15] series. Test results were collected and displayed in graphs.

\section{RESULTS AND DISCUSSION}

Altogether three different types of human balance testing boards were developed from 2015 to 2017 by researchers of Riga Technical University. Initially two balance functional capability diagnostic and improvement system prototype versions (based on employing of joystick and potentiometer sensors in conjunction with microcontrollers Arduino and other necessary electronics, such as signal amplifiers) were developed during the year of 2015 .

However, both models did not allow getting enough reliable statistical data which would be comparable with existing solutions in balance testing field, such as data obtained by BioSway and similar systems. As a result, it was decided to find new solutions which were realized in development of the third version of the prototype in 2016 as well as further updates and improvements in 2017. All created balance testing systems included balance board platform with embedded electronic equipment. The persons being tested were asked to stand on these boards and accomplish certain balance testing tasks. Next subsections give an overview of developed prototype models.

\section{A. The first, mini joystick based, model}

In the first created model (Fig. 1) the mini joystick was used as an information reader. Operating principle - mechanical movements in horizontal (X) and vertical (Y) axes were transferred into electrical signals. It allowed reading the surface shift from rotation axes. Principal scheme included microcontroller Arduino Uno and joystick linkage according recommendations provided by microcontroller producer [16].

However, the system repeatability was concluded as moderately complicated. The problem emerged 
Environment. Technology. Resources, Rezekne, Latvia Proceedings of the $11^{\text {th }}$ International Scientific and Practical Conference. Volume III, 62-68

due to difficulties to create rotation axes frame of the movable platform.

During experiments it was concluded that the shift of motion axes is too small to provide reliable enough data quantity for the joystick movements to obtain significant readable data. Besides, it was recognized that the problems with mechanical strength of the joystick could create additional problems for the long-term exploitation.

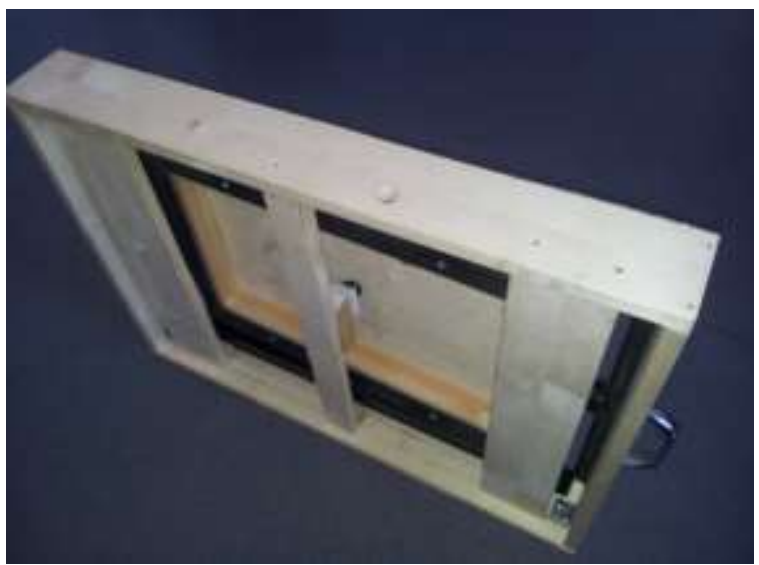

Fig. 1. Joystick mounted into the rotation centre of the platform

\section{B. The second, potentiometers based, model}

In the developed second prototype model the joystick was substituted by potentiometers which were mounted in rotation axes of the platform. The platform was taken from the first prototype model. Principal scheme included microcontroller Arduino Uno and potentiometers connection according recommendations provided by microcontroller producer [16]. To achieve the aim of diagnosis and improvement of person balance functional capabilities, consequently, for person's motion recording, the respective potentiometer mechanical transmission mechanism was implemented in this prototype model. In order to maximize the amount of movement in rotation axes, mechanical gear transmission was set with a coefficient 1:4. Practical development of the model and its realization led to the consideration that the complexity of system creation is too big, but system resistance against external electromagnetic impacts is rather high.

Taking into account recognized shortcomings of the first two developed prototype models in a prospective case of the wide spread out and massive implementation of such systems in social rehabilitation, it was decided to start development of the third prototype version of balance diagnostic and improvement system, based on utilization of the load sensor capacities. Comparative assessment of developed prototype models was made, analysing their mechanical repeatability, signal resistance against external electromagnetic impacts, mechanical strength, and system components risks (Table 1).
Table I

Comparative parameters of the developed balance testing models

\begin{tabular}{|l|l|l|l|}
\hline Factors & Model 1 & Model 2 & Model 3 \\
\hline Type & Mechanical & Mechanical & Piezoelectric \\
\hline Reader & Joystick & $\begin{array}{l}\text { Potentio- } \\
\text { meters }\end{array}$ & $\begin{array}{l}\text { Pressure } \\
\text { tensors }\end{array}$ \\
\hline $\begin{array}{l}\text { Mechanical } \\
\text { repeatability }\end{array}$ & $\begin{array}{l}\text { Moderate } \\
\text { complex }\end{array}$ & Complex & Simple \\
\hline $\begin{array}{l}\text { Signal } \\
\text { resistance } \\
\text { against external } \\
\text { electromagnetic } \\
\text { impacts }\end{array}$ & High & High & Low \\
\hline $\begin{array}{l}\text { Mechanical } \\
\text { strength }\end{array}$ & Moderate & Moderate & Moderate \\
\hline $\begin{array}{l}\text { System } \\
\text { components } \\
\text { risks }\end{array}$ & $\begin{array}{l}\text { Creation of } \\
\text { mechanical } \\
\text { part }\end{array}$ & $\begin{array}{l}\text { Creation of } \\
\text { mechanical } \\
\text { part }\end{array}$ & $\begin{array}{l}\text { Purchase of } \\
\text { tensor } \\
\text { sensor's } \\
\text { amplifier; } \\
\text { system } \\
\text { shielding }\end{array}$ \\
\hline
\end{tabular}

C. The third, load sensor based, model

We decided to choose four load sensors (tenzoresistors), mounted in balance testing board platform (a simple $2.5 \mathrm{~cm}$ thick particleboard plywood) and connected with Arduino Uno microcontroller and signal amplifiers, as these sensors are the most widely used devices for deformation measurement. To secure a place for the circuit of microcontroller and amplifiers, a special recess at the bottom of the plywood was milled hiding all sensitive parts of the system. In order to manage and monitor balance tests, the circuit of four tenzoresistors, two amplifiers and one microcontroller was connected to a laptop through USB port; this also ensured power supply for the whole system.

Operating principle of tenzoresistors is based on the electrical resistance of the driver reliance on cross-sectional area changes to mechanical deformation. Usually electrical conductor (metal wire) is glued with an insulating adhesive to the deformable material. At the loading, the material is deformed together with the adhesive layer and the electrical conductor. Deformation size shall be determined by measuring the electrical conductor resistance changes.

Further research showed, that for successful determination of the sensor output signal, tenzoresistors are connected in a certain circuit. For example, in digital scales, to determine the resistance changes, as the most common case, the resistive Wheatstone bridge circuit is used (Fig. 2). 


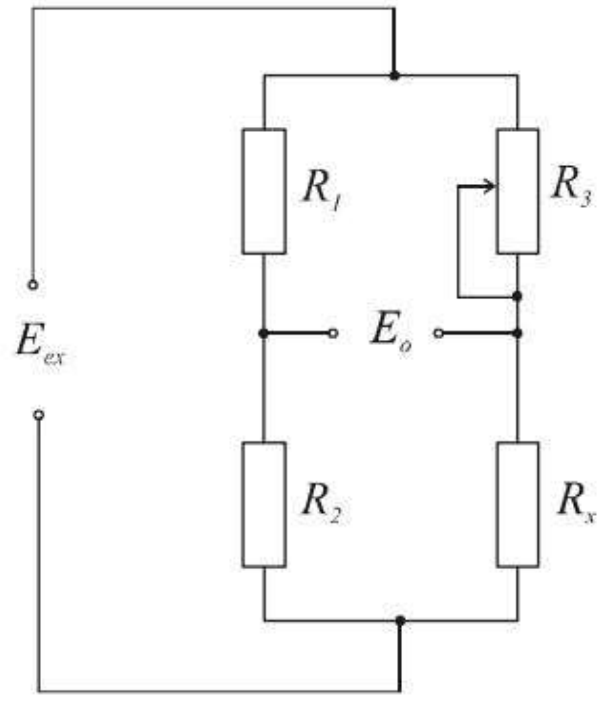

Fig. 2. Resistive Wheatstone bridge circuit

Resistive bridge theory is based on the voltage divider principles. Bridge circuit basis consists of four resistors $R_{1}, R_{2}, R_{3}$ un $R_{X}$. Resistors $R_{1}$ and $R_{2}$ usually has a high accuracy with known values, $\mathrm{R}_{3}-$ with variable resistance, and $\mathrm{R}_{\mathrm{X}}$ - with unknown resistance, which is associated with measurement transducer outputs. The voltage $\mathrm{E}_{\mathrm{ex}}$ is connected for the bridge feeding, and the bridge is balanced with the resistor $R_{3}$.

Using a multi-meter, electrical signal changes, which depend on the applied pressure, were measured. During our findings, as it was expected, we realized that the resulting signal was weak (a few millivolts) and with a low power. To ensure that this signal could be used to regulate the processes, the signal should be amplified.

This problem was solved by adding two amplifiers HX711 to the microcircuit which took care of data storage, calculation and transmission, as well amplified and transformed the obtained signal. The functionality of amplifiers allowed not only to get and amplify data from different types of sensors, but also transform them into a digital format and further transfer to "Arduino Uno" microcontroller [17].

Initially it was argued that there would be a need for four amplifiers HX711 - one for each sensor. A reason for that was following: unlike commercial scales, where the main approach was based on an implementation of the Wheatstone bridge (Fig. 2) to obtain a single value or weight, in our case we had to obtain four different values which would help reproducing the movement in the coordinate plane. In this case, it would be necessary to place appropriate resistance for each sensor which could build a quarter-bridge circuit.

Realised experiments revealed a more effective way to achieve four different values. Since the obtained data in the case of implemented half-bridge circuit (Fig. 3) can be both a positive and a negative numeral, depending on the sensor, which the power is exposed on $(\Delta \mathrm{R} 1=-\Delta \mathrm{R} 3)$, then these, now already two, values might be easily displayed on the coordinate plane as the $\mathrm{X}$ and $\mathrm{Y}$ positive and negative values, accordingly visualizing the movement on the plane.

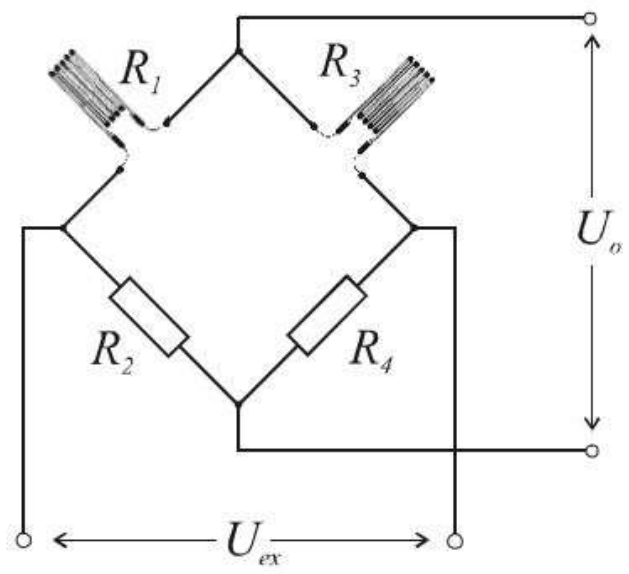

Fig. 3. Half-bridge circuit

Sensors were mounted into previously prepared particle plywood in the way to ensure that the volatility in coordinate plane could be determined as much effective as possible - each of them would give either a positive or negative value. To ensure reliability of measurement data while testing of heavy weight persons, each of four load sensors should be able to measure at least $50 \mathrm{~kg}$. Since the sensor arrangement consisted of a relatively unstable surface, the safety was provided by fitting supporting legs at each corner, which had to facilitate and improve the use of the platform.

One of the most important things, which ought to be done, is the calibration of sensors by implementing of the HX711 calibration code, which is loaded into Arduino Uno micro-controller. During modification the code is adapted for the processing from the halfbridge circuit using two amplifiers instead of one. After processing of received signal the microcontroller sends it to computer, where it is further processed by the code, created by "Processing 3.0.2" open source programming tools, which helps to interpret the received values as a moving sphere in the coordinate plane (Fig. 5 and 6).

Since gained values could be either a positive or negative numbers, it was necessary to make appropriate modifications in the previously created program. It was crucial that its newly acquired values were able to reflect also on the negative axis direction. However, "Processing" desktop started displaying from zero in the positive direction. In this case, there was defined a new zero point, which was located in the middle of the desktop instead of in the upper left corner, as usually. As a result, this approach allowed us to reflect sphere's movement also in the negative plane directions. 
Environment. Technology. Resources, Rezekne, Latvia Proceedings of the $11^{\text {th }}$ International Scientific and Practical Conference. Volume III, 62-68

Before balance functions assessment the following personal data ought to be input in the system: name and surname, age, height, duration of the test, the number of repeatable tasks / measurements and the type of the test. This information is displayed on the laptop monitor during data input (Fig. 4).

After person's data input the balance testing can start (Fig. 5 and 6). The person is asked to fulfil certain four tasks according to Modified Clinical Test of Sensory Organization and Balance (mCTSIB) test modes which already approbated in many clinical studies demonstrating test's simplicity, accessibility, usability and efficiency in balance disorder measurements [15], [18], [19].

The duration of each of four tests is set for $30 \mathrm{sec}$, the number of tasks / measurements - four times, and the person is asked to keep the moving sphere in the centre of coordinate plane precisely as much as possible (Fig. 6 and 7):

- On a hard surface, eyes open;

- On a hard surface, eyes closed;

- On a foam surface, eyes open;

- On a foam surface, eyes closed.

Test fulfilment interface (Fig. 5) gives both for the patient and medical personnel a possibility to follow all tests paces. Moving sphere's trajectories are tracked by remaining colour traces in the circle. The interface has equipped with calibration, starting, test mode selection, data acquiring and exit buttons. It displays also the patient's name and test remaining time.

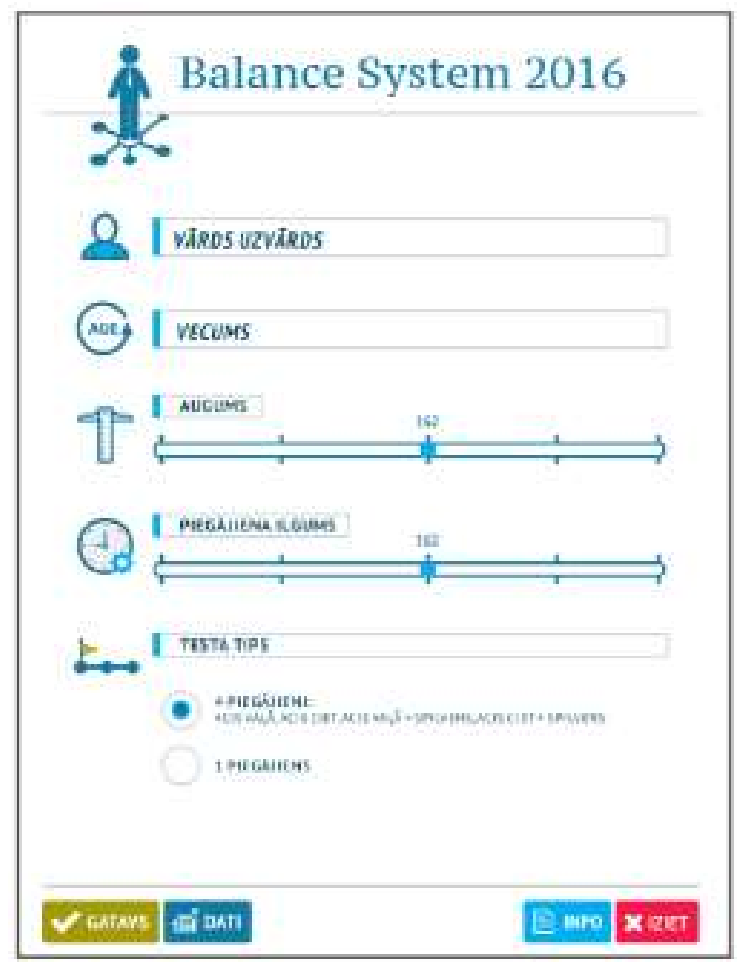

Fig. 4. Data input interface

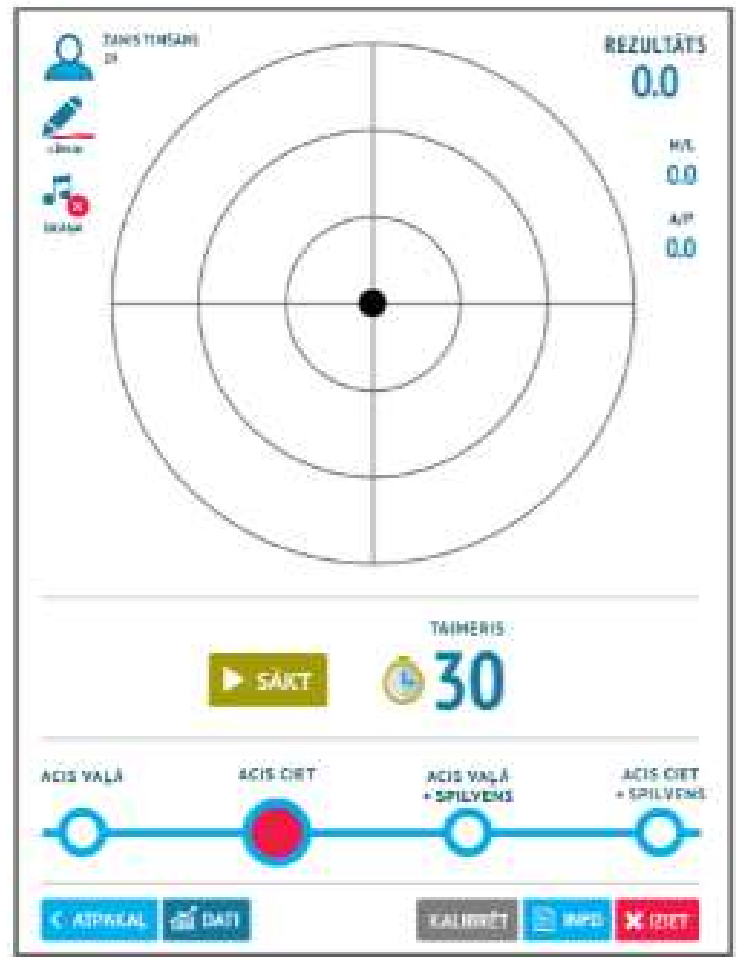

Fig. 5. Test fulfilment interface

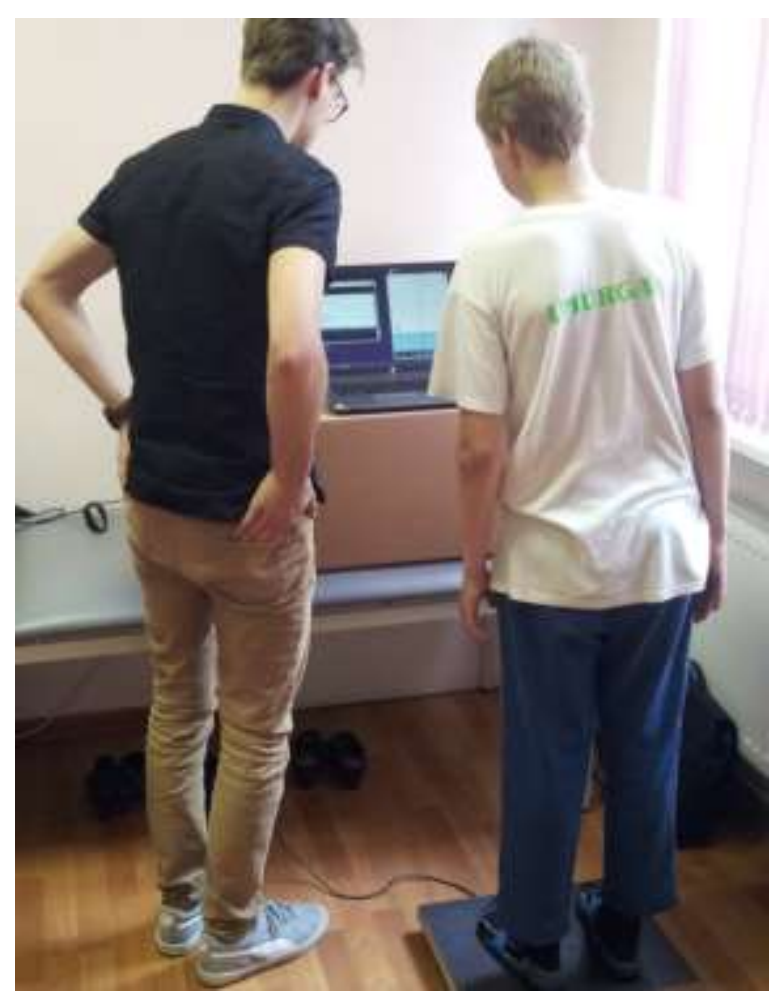

Fig. 6. Ongoing mCTSIB test

The resulting data can be summarized in the form of an Excel table (it has already carried out over two pilots / approbations as noted below in the next subsection) for further analysis and providing recommendations and guidance to the person being tested, as well to medical staff, parents and responsible personnel in educational organizations. 
Balance test results already are visualized in order to make them more usable, tangible and understandable for immediate analysis of the balance capability at the test site.

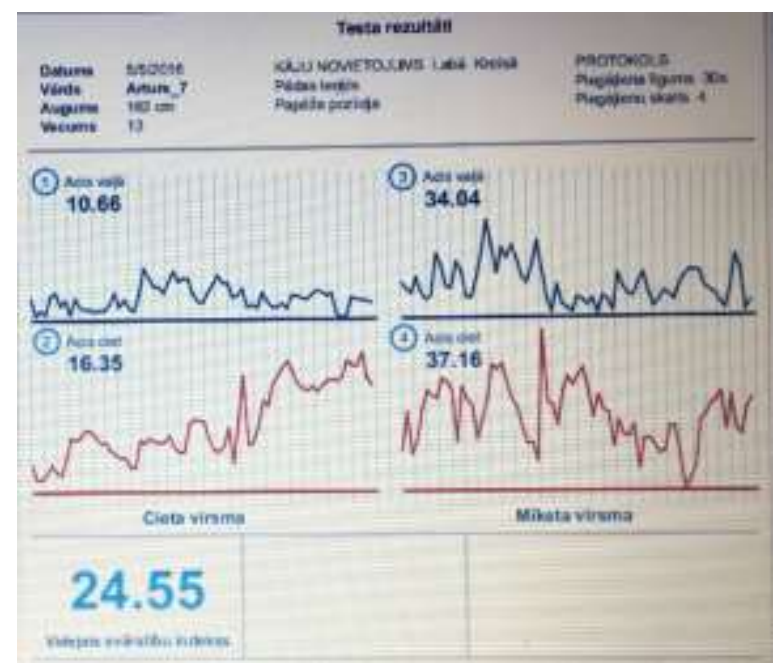

Fig. 7. Data visualization

Test results (Fig. 7) are represented in the four graphs which show patient's test results in accordance with fulfilled mCTSIB test modes: on a hard surface - eyes open and eyes closed, and on a foam surface - eyes open and eyes closed. Each of fulfilled tasks is marked by the sway index. An average sway index also is shown - the smaller the better should be. For each of test mode corresponding measurement scale ought to be developed in the next project implementation phase, allowing detection of any balance disorder.

The first trials (40 tested persons) demonstrated system ability to detect balance sways depending on test mode and person's physical capabilities. However, further large scale pilots could bring more statistical data which would allow to draw conclusions and offer practical rehabilitation instrument to be used in social rehabilitation organisations, hospitals, schools, sport teams, armed forces and so on.

\section{D.Approbation}

In 2016 two approbation pilots of the developed balance testing prototype were launched in Latvian schools in $5-7$ class pupil groups:

- 05.05.2016, in Riga Catholic Gymnasium (High School) 23 persons (22 pupils and 1 teacher) were tested;

- 26.05.2016, in Rezekne Speech Therapy Boarding Elementary School-Development Centre 17 pupils were tested.

Project group participated also in the International Invention and Innovation Exhibition MINOX-2016 in Riga in October 2016 providing valuable insight in the developed prototype capabilities. Moreover, in the fourth quarter of 2016 four broadcasts on Latvian National Television (LTV-7 Channel) were dedicated to disseminate project results and demonstrate created equipment to a wider public.

Obtained approbation data at the first estimation confirm developed balance testing third version prototype's ability to achieve defined objectives. Moreover, it should be noted that our developed balance assessment prototype is able to perform also the tasks which cannot cope commercial and more expensive system BioSway - for example, testing persons with the weight less than $40 \mathrm{~kg}$.

\section{CONCLUSIONS}

Developed prototype offers fast, demonstrative and effective human balance capability assessment. The main aim of this balance testing prototype is the early raw detection of any balance disorder. Any deflection from pre-defined sway index scale intervals will serve as a basis to make recommendations for a patient to visit a doctor.

Test results highlighted the necessity to develop corresponding measurement interval scale which would give a message about possible balance disorder. Besides, it would be useful to find relationships and correlations between person's ability to keep the balance when different external disturbing factors influence test fulfilment.

Series production of the created prototype could decrease its costs. It might be about almost ten times cheaper than existing BioSway equipment which costs around USD 7000 . Affordable price can promote prototype employment in the wide range of organisations and even at home, and as result, enhance social rehabilitation services and improve quality of life of persons with balance function disabilities.

\section{ACKNOWLEDGEMENTS}

This study has been supported by the Latvian National Research Program "Innovative solutions in social rehabilitation in Latvian schools in the context of inclusive education" (in Latvian: „Inovatīvi risinājumi sociālajā telerehabilitācijā Latvijas skolās iekḷaujošās izglītības kontekstā - VPP INOSOCTEREHI”); project No.2 „Development, approbation and implementation of new prototypes and innovative methodology (approaches, methods, techniques, ways) in social rehabilitation for the rendering of new services” (in Latvian: „Jaunu prototipu, inovatīvas metodikas (pieeju, metožu, tehniku, paṇēmienu) sociālajā rehabilitācijā izstrāde, aprobācija un ieviešana jaunu pakalpojumu sniegšanai”). Contract No. 10-4/VPP-8-7 (RTU PVS ID 1868).

\section{REFERENCES}

[1] World Health Organization, "Disability and rehabilitation: World report on disability," WHO, 2017. [Online]. Available: http://www.who.int/disabilities/world_report/2011/en/. [Accessed Mar. 14, 2017].

[2] World Health Organization and The World Bank, "World report on disability," WHO and WB, p.325, 2011. [Online]. 
Available:

http://documents.worldbank.org/curated/en/66513146833127 1288/pdf/627830WP0World00PUBLIC00BOX361491B0.pdf . [Accessed Jan. 16, 2017].

[3] W. Oortwijn, E. Nelissen, S. Adamini, S. van den Heuvel, G. Geuskens, L. Burdof, "Social determinants state of the art reviews - Health of people of working age - Summary Report," European Commission Directorate General for Health and Consumers, Luxembourg, p. 40, 2011.

[4] [4] The World Bank, "World Report on Disability: Dataset," WB, 18 October, 2013. [Online]. Available: http://data.worldbank.org/data-catalog/world-report-ondisability. [Accessed January 16, 2017].

[5] J.-M. Belda-Lois, S. Mena-del Horno, I. Bermejo-Bosch, J. Moreno, J. Pons, D. Farina, M. Iosa, M. Molinari, F. Tamburella, A. Ramos, A. Caria, T. Solis-Escalante, C. Brunner, and M. Rea, "Rehabilitation of gait after stroke: a review towards a top-down approach," Journal of NeuroEngineering and Rehabilitation, vol. 8, issue 1, article 66, Dec. 2011.

[6] B. G. Travers, P. S. Powell, L. G. Klinger, M. R. Klinger, "Motor Difficulties in Autism Spectrum Disorder: Linking Symptom Severity and Postural Stability," Journal of Autism and Developmental Disorders, vol. 43, issue 7, pp. 15681583, July 2013.

[7] Biodex Medical Systems, Inc., "Balance System SD and BioSway: Software Manual - User's Guide", Biodex, pp.164, 2016. [Online]. Available: http://www.biodex.com/sites/default/files/950440man_add_1 4074revb.pdf. [Accessed Mar. 14, 2017].

[8] C. H. Shih, C. T. Shih, M. S. Chiang, "A new standing posture detector to enable people with multiple disabilities to control environmental stimulation by changing their standing posture through a commercial Wii Balance Board," Research in Developmental Disabilities, vol. 31, issue 1, pp. 281-286, Jan.-Feb. 2010.

[9] R. A. Clark, A. L. Bryant, Y. Pua, P. McCrory, K. Bennell, \& M. Hunt, "Validity and reliability of the Nintendo Wii Balance Board for assessment of standing balance," Gait \& posture, vol. 31, issue 3, pp. 307-310, Mar. 2010.

[10] P. Scaglioni-Solano, \& L. F. Aragón-Vargas, "Validity and reliability of the Nintendo Wii Balance Board to assess standing balance and sensory integration in highly functional older adults," International Journal of Rehabilitation Research, vol. 37, issue 2, pp. 138-43, June 2014.

[11] P. Arpaia, P. Cimmino, E. De Matteis, G. D'Addio. A balance board device for home care telerehabilitation exergaming: XX IMEKO World Congress: Metrology for Green Growth, Sep. 9-14, 2012, Busan, Republic of Korea.

[12] P. Arpaia, P. Cimmino, E. De Matteis, G. D’Addio, “A lowcost force sensor-based posturographic plate for home care telerehabilitation exergaming," Measurement, vol. 51, pp. 400-410, May 2014.

[13] H. S. Cohen \& K. T. Kimball, "Usefulness of some current balance tests for identifying individuals with disequilibrium due to vestibular impairments," Journal of Vestibular Research, vol. 18, no. 5, 6, pp. 295-303, 2008.

[14] A. A. Wai, P. D. Duc, C. Syin, H. Zhang. iBEST: Intelligent balance assessment and stability training system using smartphone: Engineering in Medicine and Biology Society $(E M B C):$ The 36th Annual International Conference of the IEEE, pp. 3683 - 3686, Aug. 26-30, 2014, Chicago, USA.

[15] M. K. Park, K.-M. Kim, J. Jung, N. Lee, S. J. Hwang, \& S. W. Sung, "Evaluation of Uncompensated Unilateral Vestibulopathy Using the Modified Clinical Test for Sensory Interaction and Balance," Otology \& Neurotology, vol. 34, issue 2, pp. 292-296, Feb. 2013.

[16] Arduino, "What is Arduino?" Arduino, 2017. [Online]. Available: https://www.arduino.cc/en/Guide/Introduction /. [Accessed Feb. 1, 2017].

[17] SparkFun, "SparkFun Load Cell Amplifier - HX711," SparkFun, 2016. [Online]. Available: https://www.sparkfun.com/products/13230. [Accessed June 7, 2016].

[18] N. Murray, A. Salvatore, D. Powell, and R. Reed-Jones, "Reliability and Validity Evidence of Multiple Balance Assessments in Athletes with a Concussion," Journal of Athletic Training, vol. 49, no. 4, pp. 540-549, Aug. 2014.

[19] A. Kaupuzs, V. Larins, \& L. Rizakova. Effects of Vestibular Exercises on Postural Balance for Children: International Scientific Conference "Society. Integration. Education (SIE2016), vol. 3, pp. 453-463, Rezekne, May 27-28, 2016. 